\title{
Avifaunal Diversity in Important Bird Areas of Western Nepal
}

\author{
Saroj Shrestha ${ }^{1}$, Sony Lama², Ang Sherpa ${ }^{2}$, and Munmun Tamang ${ }^{2}$ \\ ${ }^{1}$ Red panda Network \\ ${ }^{2}$ Red Panda Network
}

September 2, 2021

\begin{abstract}
Barekot rural municipality of Jajarkot district is an Important Bird Areas (IBAs) in Western Nepal. In recent years, illegal hunting and trapping-related cases have increased in this area. Additionally, a hydropower project with a capacity of $410 \mathrm{MW}$ is being constructed within Barekot. The present study aims to update the preliminary checklist of birds and identify the underlying threats to the bird population in this region. Bird survey was conducted in four monitoring blocks of Barekot during the late winter of 2021. Also, a series of consultation meetings and interviews with the local stakeholders were organized to collect information regarding the extant threats. This study revealed eighty-seven bird species of 10 orders and 34 families. Birds most commonly recorded from the family Muscicapidae and order Passeriformes. Among the total recorded species, two species are listed in the IUCN Red List of Nationally Vulnerable Category. Similarly, five species were listed on CITES Appendix II and one species on CITES Appendix I. Approximately $82 \%$ of total bird species were of resident type. Despite a decline in bird diversity, Barekot's unique geographical location still makes it an important IBA in Nepal. Bird numbers have plummeted due to human intrusion and disturbance, and natural system modifications. Based on our findings, we recommend landscape-level research, on the impacts of hydropower projects, roads, poaching, and impacts of the Covid-19 pandemic. Similarly, future conservation efforts should also emphasize preventing habitat fragmentation and raising public awareness. Keywords: Avian community; Bird checklist; Important Bird Area; Threats
\end{abstract}

\section{Hosted file}

Main Document.docx available at https://authorea.com/users/355878/articles/536081-avifaunaldiversity-in-important-bird-areas-of-western-nepal 

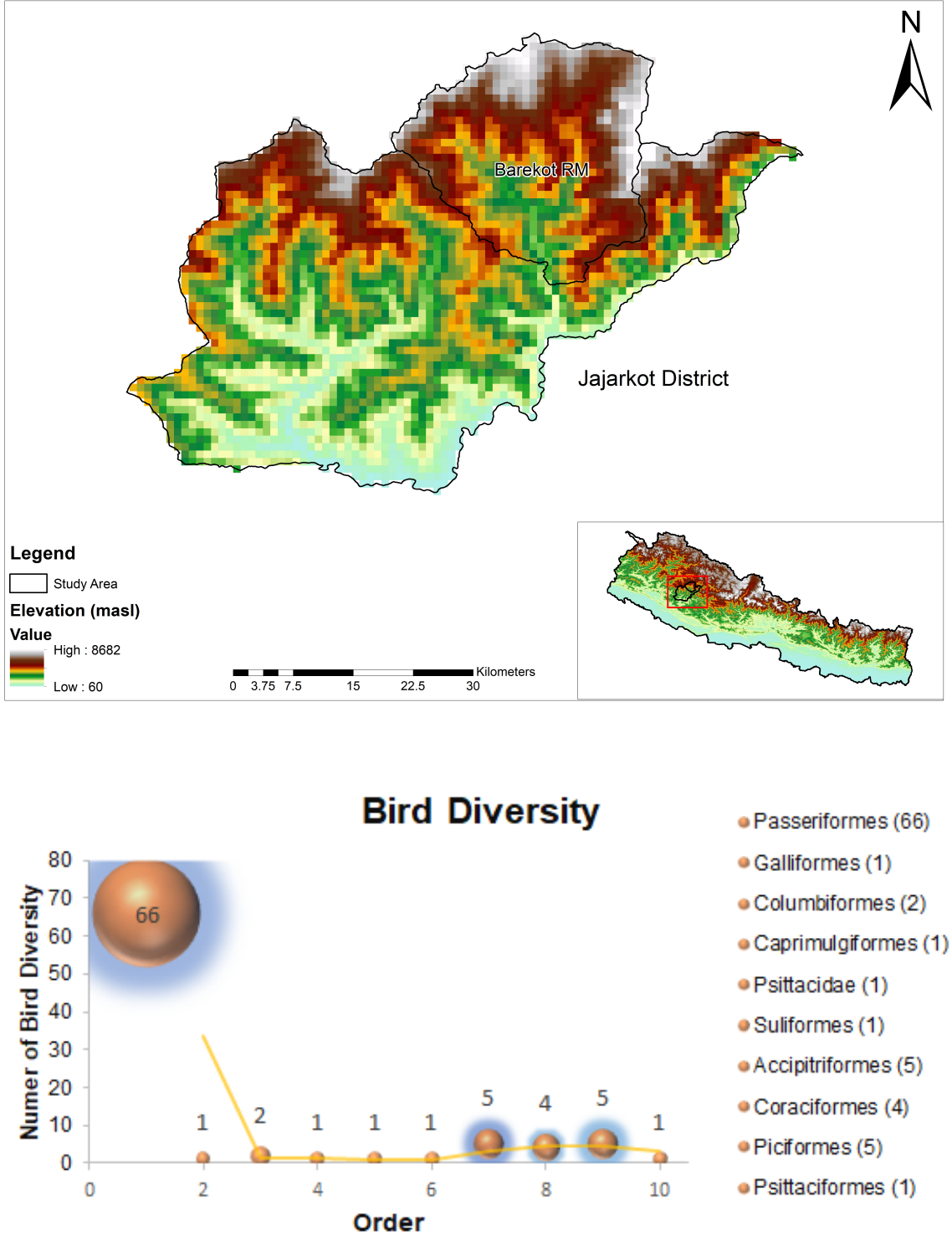

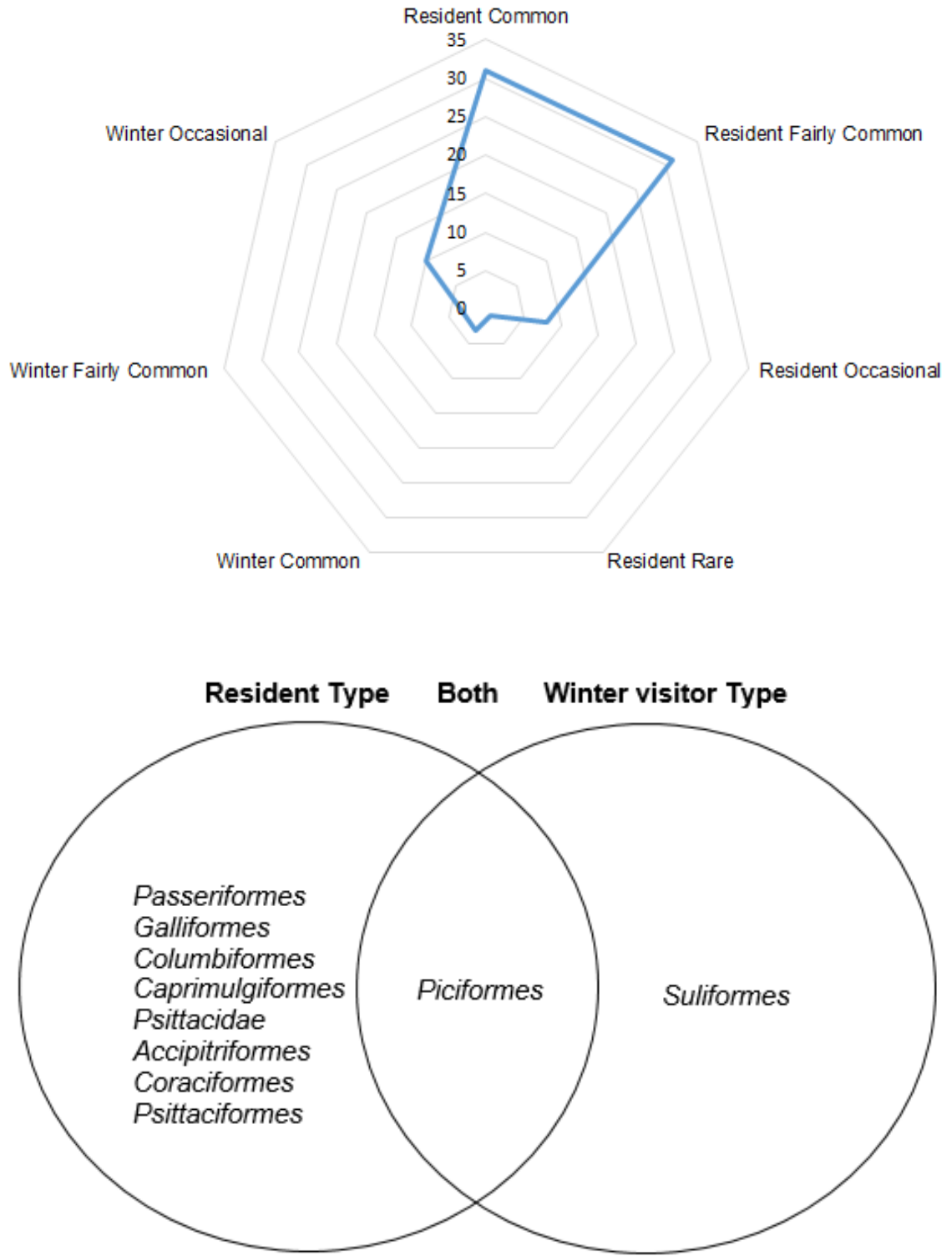